\section{Kin recognition in honeybees}

SIR - In honeybee colonies, polyandry leads to the presence of 7-20 subfamilies ${ }^{1}$. Workers can discriminate members of the same subfamily (supersisters) from workers of other subfamilies (half-sisters) ${ }^{2,3}$, and this may allow them to act nepotistically. How they discriminate is unknown, but the process is likely to involve subfamily-specific chemical labels which bees learn ${ }^{2}$. Page et $a l^{4}$ showed that laboratory-reared workers from artificial colonies with just two subfamilies had cuticle hydrocarbon profiles that were more similar between super-sisters than between half-sisters. This may not reflect the natural situation, however, where nest-mates can exchange hydrocarbons either by direct contact or through comb wax.

We have examined the cuticle hydrocarbon composition of honeybee workers from a colony headed by a naturally inseminated queen. We assigned each bee to one of 16 subfamilies using two highly variable microsatellite loci $(A 76, A 107$; ref. 1), genetic markers unrelated to cuticle hydrocarbons. To determine the relative importance of genetic and environmental factors to cuticle hydrocarbon profiles, adult bees were matured of 10 , and in their parental hive. After 5 days, workers of each set $(117,77$ and 117 bees, respectively) were individually analysed (see figure).

Hydrocarbons were extracted for 5 minutes in $1 \mathrm{ml}$ of pentane, analysed by gas chromatography (Girdel 300) on a 30-m nonpolar capillary column and constituents identified by mass spectrometry under three conditions: isolated, in groups

(Nermag R 10-10-C GC-MS). Twenty-six compounds were identified, belonging to four major classes of long-chain hydrocarbons: alkenes, alkadienes, methylbranched alkanes, but mostly $n$-alkanes. All $n$-alkanes in the $\mathrm{C}_{21}-\mathrm{C}_{33}$ series were present. Compounds with an even number of carbons predominated. For the statistical analyses, 12 compounds were excluded because their concentrations were too low to be measured reliably. The 14 remaining compounds were $\mathrm{C}_{23}, \mathrm{C}_{23: 1}, \mathrm{C}_{25}, \mathrm{C}_{27}, \mathrm{C}_{27: 1}$, $\mathrm{MeC}_{27}, \mathrm{C}_{29}, \mathrm{C}_{29: 1}, \quad \mathrm{MeC}_{29}, \mathrm{C}_{31}, \mathrm{C}_{31: 1}$, $\mathrm{MeC}_{31}, \mathrm{C}_{33: 1}, \mathrm{C}_{33: 2}$

A generalized linear model $^{5}$ (Splus 3.0) was applied to the data matrix. Each element of this matrix is the mean percentage of a given hydrocarbon for a family in a given rearing condition. Each matrix line thus represents a mean hydrocarbon profile. Our analysis shows that hydrocarbon profiles differ significantly between subfamilies. This demonstrates that these profiles are conserved even within the hive, and that cuticle hydrocarbons possess the necessary prerequisites of sufficient variability and genetic determinism for use as labels for subfamily recognition.

A potential consequence of subfamily recognition is that workers could improve the reproductive success of their own subfamily in several circumstances, such as rearing full-sister queen larvae ${ }^{6}$ or preferentially feeding their full-sister laying workers. Such nepotistic behaviour, claimed by some ${ }^{6,7}$ but denied by others ${ }^{8,9}$, implies subfamily recognition. Breed et $a l .{ }^{10}$ argued that few areas in sociobiology have received as much experimental attention, yet yielded so little in the way of supportable conclusions, as the question of subfamily nepotism in honeybees. Our demonstration of genetically determined chemical markers shows that honeybees
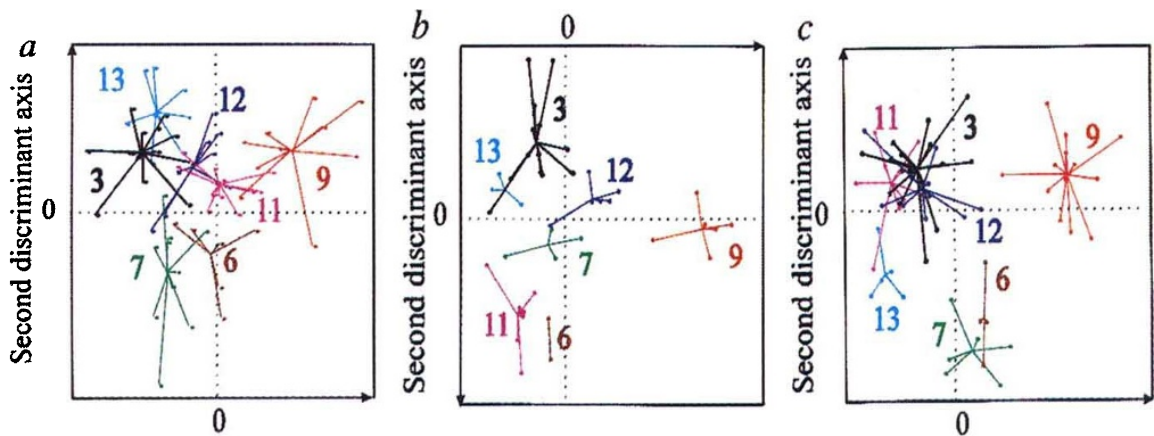

The distinctiveness of subfamily profiles is illustrated by a two-dimensional projection on the first plane of a factorial discriminant analysis (Statgraphics 7.0). First and second axes are linear combinations of the hydrocarbon concentrations. In the multi-dimensional space of the hydrocarbon profiles they form the plane where the projected distances between subfamilies are largest. In this analysis, performed on each set separately ( $a$, isolated bees; $b$, grouped bees; $c$, hive bees), only the seven best represented subfamilies were kept. Not only were bees of the same subfamily well discriminated, but the relative positions of the subfamilies in the plane remained roughly the same in the three analyses. Each subfamily is given a different colour, and bee dots of the same subfamily are linked together through their common barycentre. possess a system with sufficient discriminating power for subfamily recognition. Gérard Arnold, Brigitte Quenet Jean-Marie Cornuet, Claudine Masson Laboratoire de Neurobiologie Comparée des Invertébrés, INRA-CNRS (URA 1190),

BP 23, 91440 Bures-sur Yvette, France

Benoît De Schepper

Laboratoire de Chimie Agro-industrielle,

ENSCT, 31077 Toulouse, France

Arnaud Estoup

Laboratoire Populations, Génétique

et Evolution,

CNRS, 91198 Gif-sur-Yvette, France

Patrick Gasqui

Laboratoire de Biométrie, INRA,

78352 Jouy-en-Josas, France

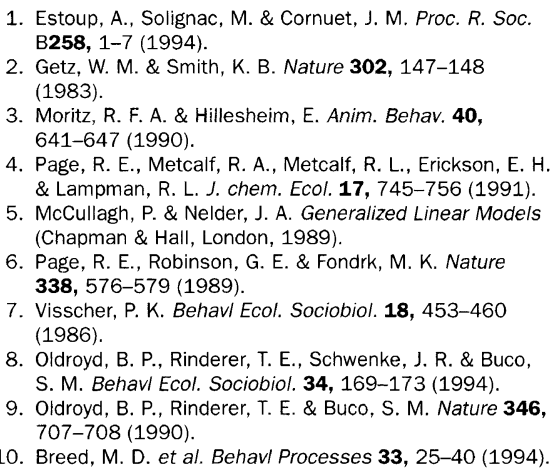

\section{Fossil mesothele spiders}

SIR-The living spiders Liphistius and Heptathela constitute the suborder Mesothelae, which is a sister group to Opisthothelae to which all other spiders belong ${ }^{1}$. Mesotheles exhibit the most primitive characteristics of all living spiders and would be expected to appear earlier in the fossil record than the oldest opisthothele, Rosamygale from Triassic (240 Myr) strata ${ }^{2}$. Indeed, many Carboniferous (355-290 Myr) spiders were once referred to this suborder ${ }^{3}$. Re-examination of all available types of Carboniferous spiders reveals that some are not spiders and that none shows autapomorphies of Mesothelae. New fossils from Montceau-les-Mines, near Autun, France, however, confirm the presence of mesotheles in the late Carboniferous (around $295 \mathrm{Myr}$ ).

The two fossils came to light in the collections of the Natural History Museums of Autun and London (details of the new species will be published elsewhere ${ }^{4}$ ). The Autun specimen ( $a, b$ in the figure) reveals a deep, narrow sternum as wide as the labium, pro- and retromarginal cheliceral tooth rows, and two opisthosomal booklung opercula. Paired internal structures lying above the second operculum and opening to its posterior border are similar to the supposed tracheal organs of Heptathela ${ }^{5}$. Posterior to the second 